\title{
Role of Protein Kinase $C$ in Substance P-Induced Synaptic Depression in the Nucleus Accumbens in vitro
}

\author{
W.C. Matowe ${ }^{a}$ K.V.V. Ananthalakshmi ${ }^{\text {b }}$ S.B. Kombian ${ }^{\text {b }}$ \\ Departments of a Pharmacy Practice and ${ }^{\mathrm{b}}$ Applied Therapeutics, Faculty of Pharmacy, Health Sciences Center, \\ Kuwait University, Kuwait
}

\begin{abstract}
Key Words
Adenylyl cyclase $\cdot$ Phosphodiesterase $\cdot$ Cyclic adenosine monophosphate $\cdot$ Protein kinase A - Excitatory synaptic transmission
\end{abstract}

\begin{abstract}
Objectives: This study set out to determine the roles of protein kinase $A(P K A)$ and protein kinase $C(P K C)$ signalling cascades in substance P- (SP-) mediated synaptic depression in the nucleus accumbens. Materials and Methods: We used whole-cell patch recording in rat forebrain slices to study the effects of excitatory and inhibitory modulators of PKA and PKC to determine their effects on SP-induced synaptic depression. Results: We showed that CAMP and PKC, but not PKA, are involved in SP-induced synaptic depression. Bath application of SP (1 $\mu \mathrm{M})$ depressed evoked excitatory postsynaptic currents (EPSCs) by $-27.50 \pm 5.6 \%(n=8)$. Pretreatment of slices with $10 \mu \mathrm{M}$ forskolin or rolipram prevented SP (1 $\mu \mathrm{M})$ from depressing evoked EPSCs $(-0.8 \pm 6.7 \%, \mathrm{n}=6$; $p>0.05$ and $1.6 \pm 5.6 \%, n=8 ; p>0.05$, respectively). Furthermore, 8-bromo cAMP (1 mM) also blocked the effect of $\mathrm{SP}(-0.5 \pm 14.8, \mathrm{n}=4, \mathrm{p}>0.05)$. However, $\mathrm{H}-89(1 \mu \mathrm{M}) \mathrm{did}$ not block the SP-induced synaptic depression $(-32.3 \pm$ $4.0 \%, n=4, p<0.05)$. By contrast, PKC inhibitors bisindolylmaleimide $(1 \mu \mathrm{M} ; 4.0 \pm 5.1 \%, \mathrm{n}=6 ; \mathrm{p}>0.05)$ and calphostin C (400 nM; -6.7 $\pm 6.5 \%, n=4, p>0.05)$ both blocked SP-induced synaptic depression. Phorbol dibutyrate caused a
\end{abstract}

synaptic depression of -33.0 . $\pm 5.0 \%$ and abolished the effect of SP $(1 \mu \mathrm{M},-5.9 \pm 8.6 \%, n=4, p>0.05)$. Conclusion: Our findings demonstrate that PKC and CAMP are involved in SP-induced synaptic depression while PKA is apparently not involved. Involvement of multiple signalling pathways may reflect the fact that SP uses several intermediates to depress EPSCs.

Copyright $\odot 2007$ S. Karger AG, Basel

\section{Introduction}

The nucleus accumbens (NAc) is a pivotal component of the brain structures involved in mediating complex and long-lasting behaviours such as learning, rewardseeking and addiction [1-3]. It is also involved in the pathogenesis of some neurological conditions such as Parkinson's disease $[1,3]$. Primary inputs into the NAc comprise dopaminergic afferents arising from the ventral tegmental area [4] as well as glutamatergic inputs coming from cortical and subcortical limbic areas $[5,6]$. These inputs are believed to regulate the activity of this nucleus so as to effect appropriate output responses after integration of the incoming signals [7-9]. Exact mechanisms of the integrative processes are not yet fully understood, but are thought to be partially dependent on the nature and status of the accumbal neurons and their abilities to process incoming signals $[10,11]$.

\section{KARGER}

Fax +4161306 1234

E-Mail karger@karger.ch

www.karger.com
(C) 2007 S. Karger AG, Basel

1011-7571/07/0162-0090\$23.50/0

Accessible online at:

www.karger.com/mpp
Dr. Wandikayi C. Matowe

Department of Pharmacy Practice, Faculty of Pharmacy

Health Science Center, Kuwait University, PO Box 24923, 13110 Safat (Kuwait)

Tel. +965 4986047 or +965 531 2300, ext. 6047, Fax +965 5342807

E-Mailw.matowe@hsc.edu.kw 
The majority of neurons in the NAc $(>90 \%)$ are GABAergic medium spiny projection neurons, which are normally quiescent until stimulated by incoming signals. They exert a robust inhibition of neighbouring cells through an extensive network of axon collaterals [2, 1214]. Substance $P(\mathrm{SP})$, an excitatory peptide neurotransmitter that is co-localized with GABA in these projection neurons, inhibits evoked synaptic responses in the NAc, resulting in the depression of both inhibitory and excitatory postsynaptic currents (IPSCs, EPSCs) recorded in the nucleus $[15,16]$. Although SP has been reported to utilize intermediate neuromodulators such as dopamine and adenosine, the intracellular molecular mechanisms underlying the SP-induced inhibitory effects is a matter for conjecture at present. We have started to unravel these mechanisms by examining the possible pathways and mechanisms involved by investigating two key signalling pathways mediating signal transduction within this nucleus. Preliminary data suggests that protein kinase A (PKA) and protein kinase $\mathrm{C}$ (PKC) may play key roles in modulating the amplitude of EPSCs and IPSCs in the NAc [Kombian, personal commun.]. The effects of these two kinases are achieved through phosphorylation of their key targets which include transporters of modulators or transmitters, ion channels, and regulatory proteins involved in the transduction cascade through phosphorylation and dephosphorylation reactions [17-19]. Such targets are known to mediate or regulate synaptic transmission.

In this study we examined the potential downstream signalling pathways following SP activation of its preferred receptor, the NK1 receptor, and the possible roles of PKA and PKC in the observed depressant effect on EPSCs downstream of the receptor. We also examined the possible involvement of $\mathrm{PKC}$ on adenosine effect on the EPSC amplitude in the NAc as adenosine is reported to be the final mediator of the SP-depressant effect on EPSC.

\section{Materials and Methods}

All experiments in this study were carried out on rats obtained from the Kuwait University Animal Resource Centre. International guidelines on humane handling of animals, as established by the Canadian Council on Animal Care (1993), were followed throughout this study and the minimum number of animals necessary to produce the required results was used. Forebrain slices containing the NAc and the cortex were generated using previously published techniques [20]. Briefly, male Sprague-Dawley rats $(100-150 \mathrm{~g})$ were anaesthetized with halothane before decapitation. The brain was quickly removed from the rat and placed in ice-cold $\left(4^{\circ} \mathrm{C}\right)$ artificial cerebrospinal fluid (ACSF) that was bubbled with $95 \% \mathrm{O}_{2}$ and $5 \% \mathrm{CO}_{2}$. The composition of the ACSF was (in mM): $126 \mathrm{NaCl}, 2.5 \mathrm{KCl}, 1.2 \mathrm{NaH}_{2} \mathrm{PO}_{4}, 1.2 \mathrm{MgCl}_{2}, 2.4$ $\mathrm{CaCl}_{2}, 18 \mathrm{NaHCO}_{3}, 11$ glucose. Parasagittal forebrain slices (400 $\mu \mathrm{m}$ thick) were cut in the ice-cold ACSF using tissue slicers [Electron Microscopy Sciences (OTS-4000) or Leica (VT 1000S)]. Slices were incubated in ACSF (bubbled with $95 \% \mathrm{O}_{2}$ and $5 \% \mathrm{CO}_{2}$ ) at room temperature and allowed to recover for at least $1 \mathrm{~h}$. One slice was then transferred into a $500-\mu \mathrm{l}$ capacity recording chamber and perfused (submerged) with ACSF that was continuously bubbled with $95 \% \mathrm{O}_{2}$ and $5 \% \mathrm{CO}_{2}$ at a flow rate of $2-3 \mathrm{ml} / \mathrm{min}$ $\left(28-31^{\circ} \mathrm{C}\right)$.

'Blind patch' whole-cell recordings were done using glass electrodes with tip resistance of 4.0-8.0 $\mathrm{M} \Omega$. After the formation of a gigaohm $(>1 G \Omega)$ seal, the membrane under the seal was ruptured giving series/access resistance of 15-30 $\mathrm{M} \Omega$. The composition of the internal solution was (in mM) $135 \mathrm{~K}$-gluconate, $8 \mathrm{NaCl}$, 0.2 EGTA, 10 HEPES, 2 Mg-ATP, 0.2 GTP; pH and osmolarity were adjusted to 7.3 and $270-280$ mosm, respectively. Bipolar tungsten stimulating electrodes were placed at the prefrontal cortex-accumbens border to evoke synaptic responses. Recordings were made using Axopatch 1D amplifiers in voltage clamp mode without series resistance compensation. Reported resting potential for each cell was corrected for liquid junction potential by estimating the offset at the end of each experiment and adding it to the potential that was determined immediately after acquiring the cell.

Cells were voltage-clamped at $-80 \mathrm{mV}$ and input $\left(\mathrm{R}_{\text {input }}\right)$ and access resistance $\left(R_{a}\right)$ of all cells was monitored regularly throughout each experiment by applying a $20-\mathrm{mV}$ hyperpolarizing pulse for $75 \mathrm{~ms}$. $\mathrm{R}_{\text {input }}$ was calculated from the steady-state current obtained during the pulse. The decay rate $(\tau)$ of the capacitance transient was taken as a measure of $R_{a}$. Data from cells that showed $>15 \%$ change in $R_{a}$ were excluded from further analysis.

Evoked non-NMDA receptor-mediated pure EPSCs were isolated both pharmacologically, using $50 \mu \mathrm{M}$ picrotoxin, and biophysically by voltage clamping cells at $-80 \mathrm{mV}$. Picrotoxin was present in the bath throughout each experiment. These evoked EPSCs were verified to be pure, non-NMDA receptor-mediated responses by their complete abolition in the presence of the nonNMDA receptor antagonist 6,7-dinitroquinoxaline-2,3-dione (DNQX, $10 \mu \mathrm{M})$. Except where indicated, all experiments in this report were conducted using these pharmacologically isolated evoked EPSCs.

All cells had a graded evoked synaptic response to increasing stimulus intensity (ranging from 0.2 to $4.0 \mathrm{~mA}$ ); and an intensity giving $50-60 \%$ of the maximum evoked EPSC was used to evoke test responses except where indicated otherwise. All data were acquired using pClamp Software (Clampex 7 or 8; Axon Instruments) at sampling rates of $6.6 \mathrm{kHz}$ and filtered at $1 \mathrm{kHz}$, digitized at $10 \mathrm{kHz}$ and stored for off-line analysis. In some experiments hard copy chart records were also captured on HP or Gould chart recorders.

Excitatory postsynaptic current and potential amplitudes were measured from baseline to peak and taken as the synaptic strength at the chosen stimulus intensity. Responses were normalized by taking the mean of the last 3-4 responses prior to drug application and dividing the rest of the responses by this mean. These normalized values were then used for average plots. For 
these plots, all cells receiving the same treatment were aligned at the first minute of drug application and averaged over the entire period. All values are stated as mean \pm standard error unless otherwise indicated. One-way ANOVA and post-hoc tests, as indicated in the 'Results' section, were used to compare different values or treatments $\left(\right.$ SigmaStat $\left.{ }^{\circledR}\right)$. Significance was taken at the level of $p \leq 0.05$. Graphing was done using SigmaPlot ${ }^{\circledR}$ and CorelDraw ${ }^{\circledR}$ software.

Except where indicated, all drugs were bath-perfused at final concentrations indicated by dissolving aliquots of stock in the ACSF. SP and routine laboratory chemicals were from Sigma Co. (Steinheim, Germany), DNQX, rolipram and forskolin were obtained from RBI (Natick, Mass., USA), and bisindolylmaleimide IV, H-89, calphostin C, phorbol-12-13-dibutyrate and dideoxyforskolin were obtained from Calbiochem (Darmstadt, Germany). Stock solutions of these second messenger activators and inhibitors were made in manufacturer-suggested solvents, frozen at $-20^{\circ} \mathrm{C}$ and used within 3 days.

\section{Results}

The results reported in this study were obtained from recordings in NAc cells using the 'blind' conventional whole-cell recording technique. These cells had an average resting membrane potential of $-76.3 \pm 1.2 \mathrm{mV}(\mathrm{n}=$ $49)$ and input resistance at rest of $165 \pm 6.2 \mathrm{M} \Omega(\mathrm{n}=20)$. All cells were voltage-clamped at $-80 \mathrm{mV}$ and pure EPSCs were isolated by blocking $\mathrm{GABA}_{\mathrm{A}}$ receptor-mediated inhibition with $50 \mu \mathrm{M}$ picrotoxin. The remaining inward synaptic currents were pure non-NMDA receptor-mediated EPSCs as they were completely abolished by $10 \mu \mathrm{M}$ DNQX (fig. 1A).

\section{SP-Induced Depression of Evoked Excitatory Synaptic}

Responses Is Blocked by Increasing Intracellular Cyclic Adenosine Monophosphate (cAMP) Levels

Bath application of SP $(1 \mu \mathrm{M})$ for 5-6 min caused a decrease in the amplitude of evoked non-NMDA receptor-mediated EPSCs by $-27.5 \pm 5.6 \%(\mathrm{n}=8$, fig. 1$)$. The onset of action was between 2 and 3 min with a peak effect in about 5-6 min. In addition, recovery from the effect of SP was only partial as previously reported (fig. 1).

Receptors that are coupled to the cAMP system usually increase the intracellular level of this substance by activating the enzyme adenylyl cyclase. To examine whether the cAMP/PKA system was involved in the actions of SP, we first activated adenylyl cyclase using forskolin. When slices were pretreated with forskolin $(10 \mu \mathrm{M})$ for $5-8 \mathrm{~min}$, there was a significant increase in the amplitude of the evoked EPSC (39.0 $\pm 17.6 \%$; $\mathrm{p}<$ $0.05 ; \mathrm{n}=6$; fig. 2 ) as previously shown by Harvey and Lacey [21]. When SP $(1 \mu \mathrm{M})$ was subsequently applied at
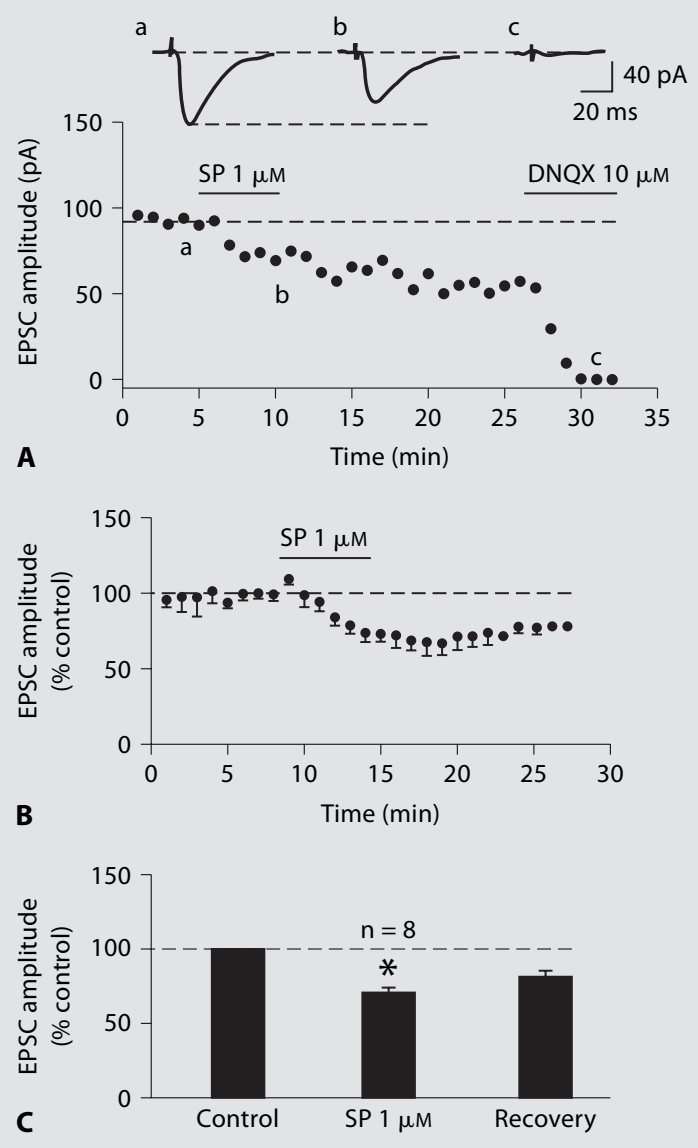

Fig. 1. SP depresses evoked, non-NMDA receptor-mediated EPSCs in the NAc. A Time-effect plot in a typical NAc neuron voltage clamped at $-80 \mathrm{mV}$. Bath application of SP $(1 \mu \mathrm{M})$ caused a decrease in the evoked EPSC recorded in the presence of picrotoxin $(50 \mu \mathrm{M})$. Following several minutes' washout, the response was verified to be pure non-NMDA receptor-mediated by its complete abolition by DNQX $(10 \mu \mathrm{M})$. The upper panel shows representative synaptic traces taken from the times indicated by letters in the lower panel. In this and all other plots, the beginning and length of the bar below each drug represent the beginning and duration, respectively, of that drug application. B An average time-effect plot $(n=8)$ of the effect of $1 \mu \mathrm{M}$ SP on pure EPSCs. C An average bar graph summarizing the effects of SP $(1 \mu \mathrm{M})$ and the partial recovery following a $10-$ to $15-\mathrm{min}$ washout of SP. ${ }^{*} \mathrm{p}<0.05$ compared to control.

the peak of the forskolin-induced synaptic enhancement, it had no significant effect on the amplitude of the EPSC $(2.0 \pm 7.1 \%, \mathrm{n}=6, \mathrm{p}>0.05$ compared to the response in the presence of forskolin alone; paired t test; fig. 2). In 

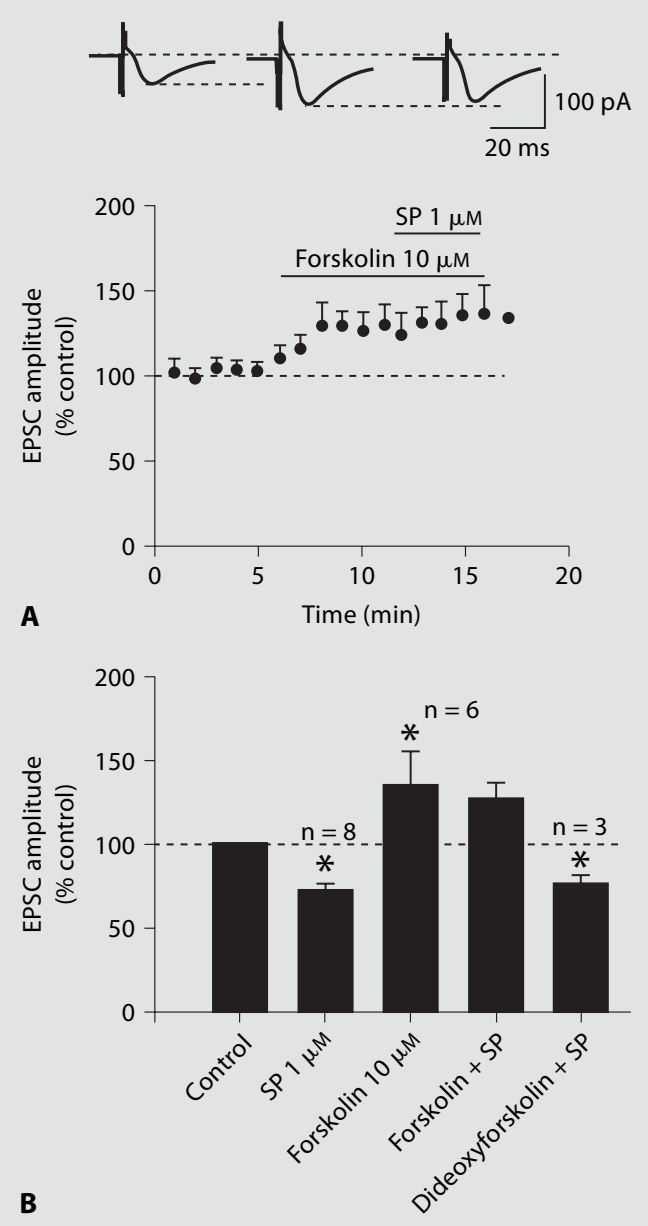

Fig. 2. Activation of adenylyl cyclase blocks the SP-induced depression of evoked non-NMDA receptor-mediated EPSCs in the NAc. A An average time-effect plot $(n=6)$ of evoked EPSCs showing that forskolin $(10 \mu \mathrm{M})$ by itself caused an increase in the EPSC amplitude. When SP $(1 \mu \mathrm{M})$ was subsequently applied at the peak of the forskolin effect, it no longer produced a decrease in EPSC amplitude. The upper panel shows representative EPSC traces taken from one of the cells below in control, in the presence of forskolin alone and the combined presence of forskolin and SP. B An average bar graph illustrating the effect of forskolin $(n=6)$ and dideoxyforskolin $(\mathrm{n}=3)$ on SP-induced EPSC depression. * $\mathrm{p}<0.05$ compared to control.

contrast, the inactive analog of forskolin (dideoxyforskolin) neither increased the evoked EPSC amplitude nor blocked the actions of SP $(1 \mu \mathrm{M})$ as the latter still produced a significant decrease in evoked EPSC amplitude $(-20.3 \pm 5.4 ; \mathrm{p}<0.05 ; \mathrm{n}=3)$.
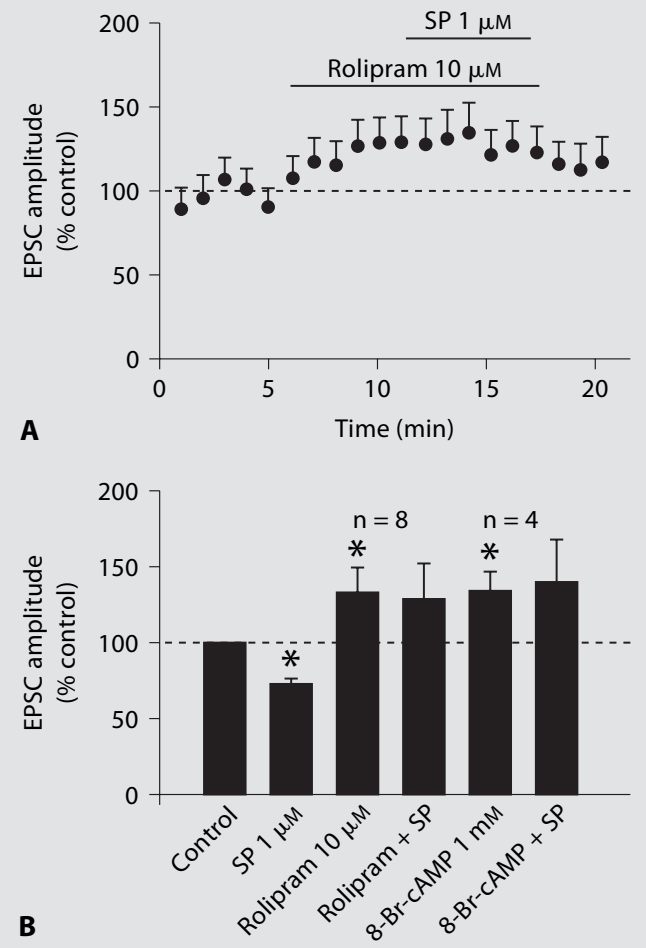

Fig. 3. SP-induced synaptic depression is blocked by other intracellular cAMP-modifying compounds. A Average time-effect plot obtained from eight cells showing that, like forskolin, rolipram also caused an increase in evoked EPSC amplitude. When SP $(1 \mu \mathrm{M})$ was applied in the presence of rolipram $(10 \mu \mathrm{M})$, there was no synaptic inhibition. B A bar graph comparing the effects of SP $(1 \mu \mathrm{M})$ in control (from fig. 1) and in the presence of rolipram and 8 -Br-cAMP, a membrane-permeable cAMP analog $(n=4)$. The latter also enhanced EPSC amplitude and blocked SP-induced synaptic depression. ${ }^{*} \mathrm{p}<0.05$ compared to control.

When cAMP is generated in situ, it is broken down by phosphodiesterases (PDEs) into inactive metabolites to terminate its action. Inhibition of PDE therefore causes an increase in intracellular cAMP levels, producing effects similar to activation of adenylyl cyclase. When we bathapplied rolipram $(10 \mu \mathrm{M})$, a cAMP-specific PDE inhibitor, an effect similar to forskolin, i.e., an enhancement in evoked EPSC amplitude was recorded $(28.9 \pm 11.0 \%$; $\mathrm{p}<$ $0.05 ; \mathrm{n}=8$, paired t test; fig. 3 ). When SP $1 \mu \mathrm{M}$ was subsequently applied at the peak of the rolipram-induced synaptic enhancement, SP no longer caused a significant decrease in evoked EPSC amplitude $(-1.6 \pm 5.6 \%, n=8$; 


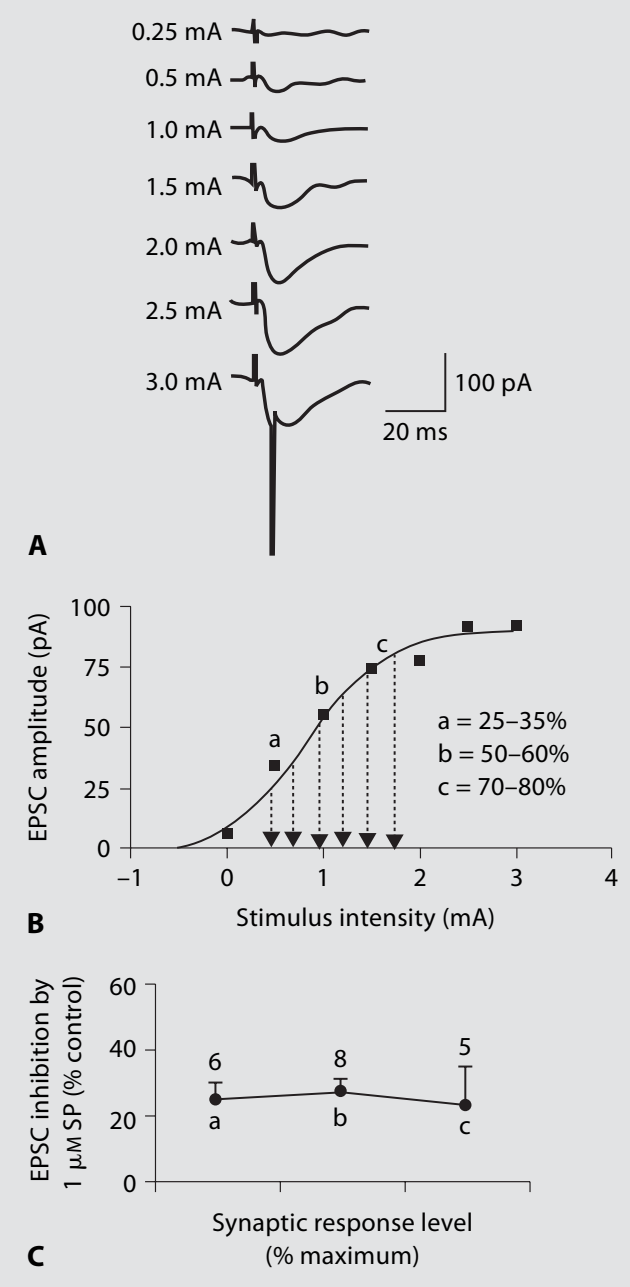

Fig. 4. SP-induced EPSC depression is independent of synaptic strength. A Sample EPSCs in an NAc neuron showing that the EPSC is graded such that increasing the stimulus intensity yields EPSCs of higher magnitude until action potential threshold is reached when the cell fires an action potential on top of the EPSC (last trace). B Stimulus intensity-EPSC amplitude plotted to show the graded nature of the response. Arrowheads and broken lines demarcate the three synaptic strength levels that were tested ( $a, b$ and c). C Average plot of the magnitude of EPSC depression at the above three synaptic strengths ( $a, b$ and $c)$. The number above each point represents the number of cells tested at that synaptic strength. Note that $b$ is data from control SP experiments (fig. 1).

$p>0.05$ compared to the response in the presence of rolipram; paired t test; fig. 3). To further explore the role of cAMP in the effect of SP on evoked EPSCs, we bath-applied a membrane-permeant analog of cAMP, 8-Br-cAMP
(1 mM), and subsequently tested the effect of SP. Similar to the effects produced by forskolin and rolipram reported above, a 6- to 8-min application of 8-Br-cAMP caused an enhancement in evoked EPSCamplitude $(37.5 \pm 18.2 \%$, $\mathrm{n}=4, \mathrm{p}<0.05$ compared to control, paired t test, fig. $3 \mathrm{~B}$ ). SP $(1 \mu \mathrm{M})$ did not decrease the evoked EPSC amplitude when applied at the peak of the 8-Br-cAMP effect $(0.5 \pm$ $14.8 \%, \mathrm{n}=4 ; \mathrm{p}>0.05$ compared to the response in $8-\mathrm{Br}$ cAMP; paired t test; fig. 3B). The inability of SP to depress EPSC in the presence of forskolin and the other intracellular cAMP modulators was not due to the increase in EPSC amplitude induced by these compounds since, as demonstrated in figure 4, SP caused a similar level of EPSC depression regardless of the synaptic strength at which it was applied. Thus, the ability of all these compounds, which increase intracellular cAMP levels, to obviate the actions of SP suggests that SP may modulate cAMP levels through adenylyl cyclase or PDE, which then results in activation of downstream processes to ultimately lead to a decrease in evoked EPSC amplitude.

\section{SP-Induced Synaptic Depression Does Not Involve Activation of PKA}

The best characterized physiological effects of cAMP are those mediated through PKA, a kinase that is thought to couple most adenylyl cyclase-dependent receptors to their output responses [for review see ref. 22]. To determine if SP's actions follow this conventional pathway, we attempted to inhibit PKA to see if SP still caused a decrease in evoked EPSC. An 8- to 10-min application of the PKA-selective inhibitor $\mathrm{H}-89(1 \mu \mathrm{M})$ caused a slight but insignificant increase $(12.7 \pm 20.7, \mathrm{p}>0.05 ; \mathrm{n}=4$; fig. $5 \mathrm{~A})$ in evoked EPSC amplitude. When SP $(1 \mu \mathrm{M})$ was applied at the peak of this effect, there still was a significant decrease in evoked EPSC amplitude $(-32.3 \pm 4.0 \%, n=4$; $\mathrm{p}<0.05$ compared to control, paired t test; fig. 5A, B), an effect that was not different from that induced by SP alone ( $p>0.05$, unpaired $t$ test). The inability of H-89 to block the SP effect was not due to inadequate application time or concentration as the same protocol and concentration of $\mathrm{H}-89$ was able to block the rolipram-induced EPSC enhancement ( $\mathrm{n}=5$; fig. $5 \mathrm{~B})$ that is known to be PKA-dependent. These results indicate that although SP works by altering CAMP levels, the downstream processes mediating the EPSC depression does not involve PKA.

\section{SP-Induced Synaptic Depression Involves Activation of $P K C$}

We previously reported that SP caused excitatory synaptic depression in this nucleus by increasing the extra- 

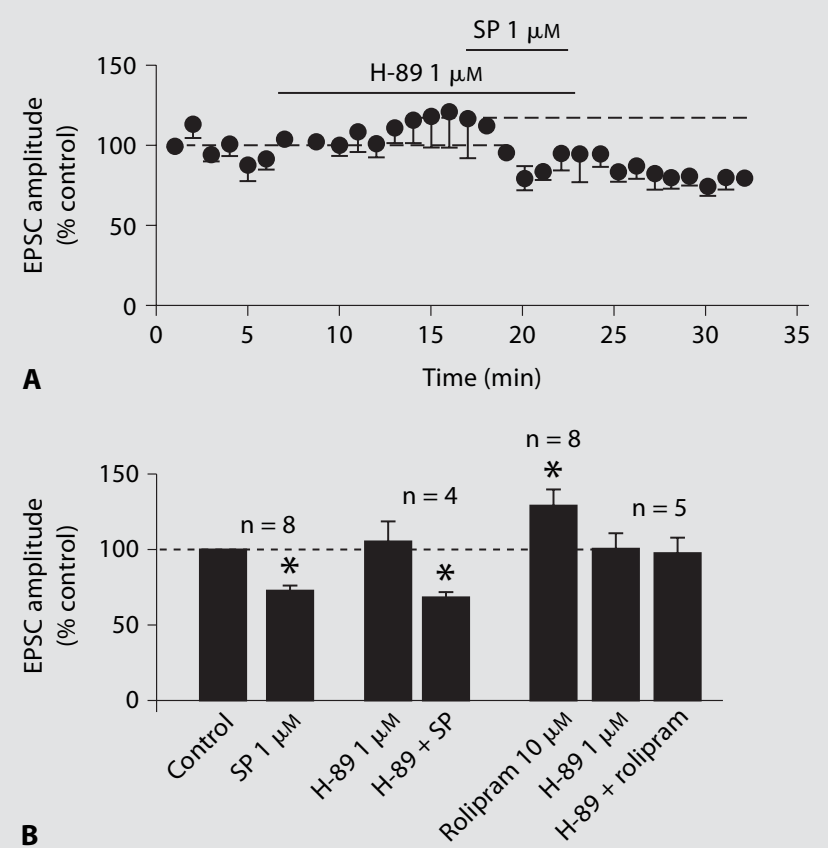
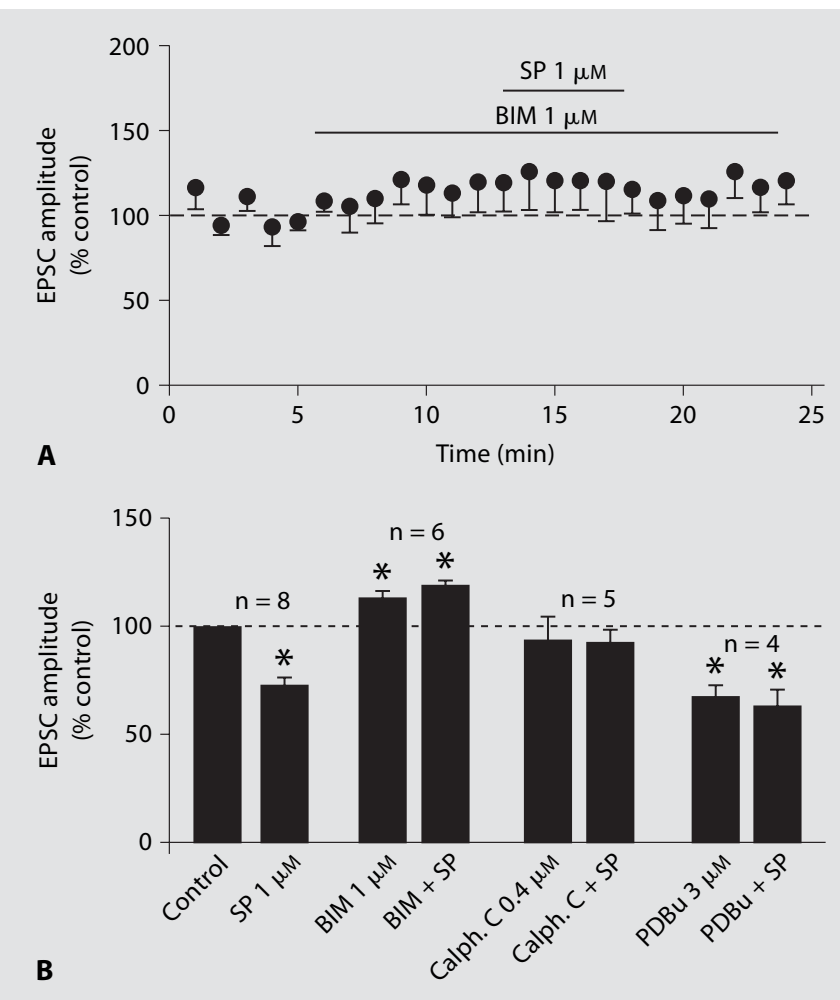

Fig. 6. SP-induced synaptic depression is blocked by either inhibition or activation of PKC. A An average time-effect plot obtained from six cells showing the effect of a PKC inhibitor BIM $(1 \mu \mathrm{M})$ alone and in the presence of SP $(1 \mu \mathrm{M})$ on evoked EPSC amplitude. B Bar graph comparing the effect of SP alone (taken from fig. 1) and in the presence BIM $(1 \mu \mathrm{M} ; \mathrm{n}=6)$ and another PKC inhibitor, calphostin C (Calph. C, $400 \mathrm{nM} ; \mathrm{n}=5)$. Also included is the effect of PDbu $(3 \mu \mathrm{M} ; \mathrm{n}=4)$, a PKC activator alone and in combination with SP. ${ }^{*} \mathrm{p}<0.05$ compared to control. cellular levels of dopamine. Furthermore, it has been demonstrated that dopamine acts to increase extracellular levels of adenosine. Adenosine is then thought to mediate the decrease in glutamate release, resulting in the observed suppression of evoked EPSC amplitude. Several investigators have recently shown that dopamine's action to decrease EPSC amplitude in this and other nuclei is blocked by PKC inhibitors. Since the actions of SP are via dopamine, it would be predicted that inhibition of PKC would also block the synaptic effects of SP. To test the hypothesis that PKC is involved in SP's actions, we used activators and selective PKC inhibitors. Pretreatment of the slice with a PKC-selective inhibitor bisindolylmaleimide IV (BIM, $1 \mu \mathrm{M})$ for 8-10 min resulted in blockade of the SP-induced synaptic depression $(-4.0 \pm 5.1 \%, \mathrm{n}=6$, $p>0.05$ compared to control response, unpaired t test; fig. 6A, B). Another PKC-selective inhibitor, calphostin C (400 nM), also blocked the effect of SP, resulting in a depression of only $-6.7 \pm 6.5 \%(n=4 ; p>0.05$ compared to control response; fig. 6B). The blockade of SP-induced EPSC depression by these inhibitors of PKC indicates that SP or its intermediate modulators dopamine and/or adenosine may activate PKC to produce the observed synaptic depression. If this is the case, then maximal activation of PKC with a PKC activator should block or occlude SP's effects.

To test this hypothesis, we used a relatively high concentration of the PKC activator, phorbol-12,13-dibutyrate $(\mathrm{PDBu})$ to maximally activate this enzyme. When slices were pretreated with PDBu $(3 \mu \mathrm{M})$, a synaptic de- 
pression similar in magnitude to that produced with SP was observed $(-33.9 \pm 5.0 \%, \mathrm{n}=4, \mathrm{p}<0.05$ compared to control response, paired t test; fig. 6B). When SP was subsequently applied in the presence of $\mathrm{PDBu}$, the synaptic depression was insignificant $(-5.9 \pm 8.6 \%, \mathrm{n}=4, \mathrm{p}>0.05$ compared to the response in the presence of $\mathrm{PDBu}$ alone; paired t test; fig. 6B).

Finally, to test if adenosine also utilized PKC to mediate the synaptic depression, we tested the effect of calphostin $\mathrm{C}$ on adenosine-induced synaptic depression in this nucleus. Bath application of adenosine $(10 \mu \mathrm{M})$ depressed the evoked EPSC by $-29.3 \pm 1.8 \%(\mathrm{n}=8, \mathrm{p}<0.05$; fig. 7). When cells were pretreated first with calphostin $C$ (400 $\mathrm{nM}$ ) and adenosine $(10 \mu \mathrm{M})$ was subsequently applied, adenosine still produced a significant EPSC depression $(-35.2 \pm 4.8 \%, \mathrm{n}=4, \mathrm{p}>0.05$ compared to control adenosine effect, unpaired t test; fig. 7B, C) although when 2 of these cells were subsequently challenged with SP $(1 \mu \mathrm{M})$, the depressant effect of SP was blocked $(-5.8$ $\pm 11.0 \%$; mean $\pm \mathrm{SD}$; fig. $7 \mathrm{C})$, indicating that calphostin $C$ was active in these experiments. Taken together with other reports our results indicate that SP and dopamine, but not adenosine, utilize PKC or require its activation to produce the observed synaptic depression.

\section{Discussion}

In the present study we have demonstrated that SP, through its preferred receptor, the NK1 receptor, couples to PKC to produce EPSC depression in the NAc. It accomplishes this by mobilizing dopamine and adenosine through a mechanism that is not yet clearly determined to mediate this depression.

The complex organization and interconnectedness of NAc neurons and their spatiotemporal relationships make it difficult to discern origins of signals, and the cellular and synaptic responses they elicit. However, the reported characteristics and percentages of cell types in the NAc support the hypothesis that production of evoked glutamatergic EPSCs is through stimulation of incoming glutamatergic afferents from the prefrontal cortex $[6,23$, 24].

The majority of SP-preferring NK1 receptors in the NAc are found on terminals and sparse cholinergic interneurons which comprise about $2 \%$ of the cells, but provide very dense local innervation [25]. These interneurons are reported to modulate levels of dopamine within the nucleus. SP, co-released with GABA from the projection medium spiny GABAergic neurons is also known to
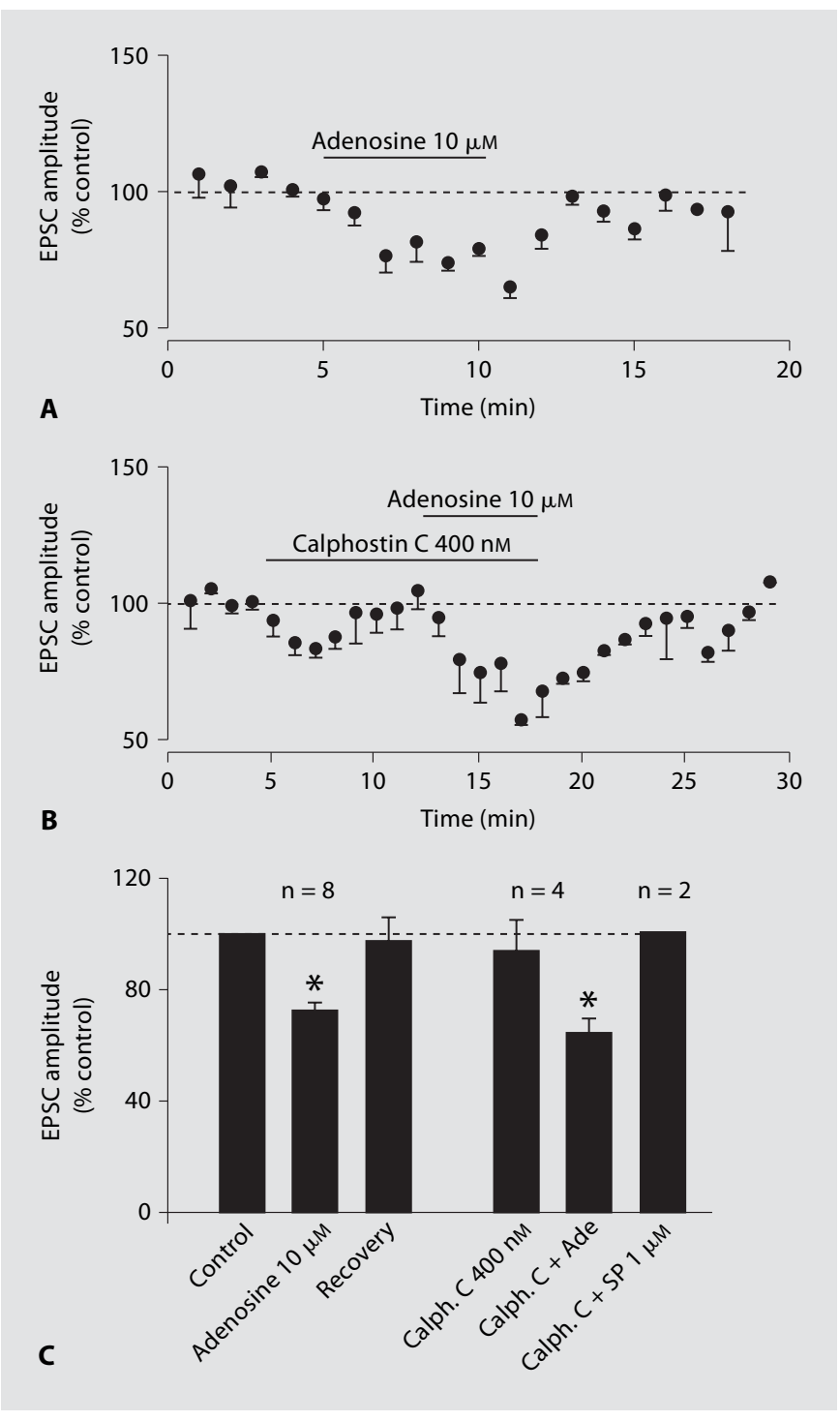

Fig. 7. Adenosine-induced synaptic depression is not blocked by inhibition of PKC. A An average time-effect plot obtained from eight cells showing the effect of adenosine alone on evoked EPSC amplitude. B An average time-effect plot obtained from four cells that were pre-treated with calphostin C (400 nM) followed by adenosine $(10 \mu \mathrm{M})$. C Bar graph comparing the effect of adenosine alone and in the presence calphostin C (Calph. C; $400 \mathrm{nM}$ ). Also included here is a bar demonstrating the lack of effect of SP in two of the above cells. ${ }^{*} \mathrm{p}<0.05$ compared to control.

control dopamine levels in this nucleus [26]. The exact mechanism by which SP causes dopamine release is not clear but there are two plausible pathways by which it can accomplish this: (i) SP directly excites dopaminergic terminals in the NAc to cause dopamine release or (ii) it excites the cholinergic interneurons to release acetylcholine 


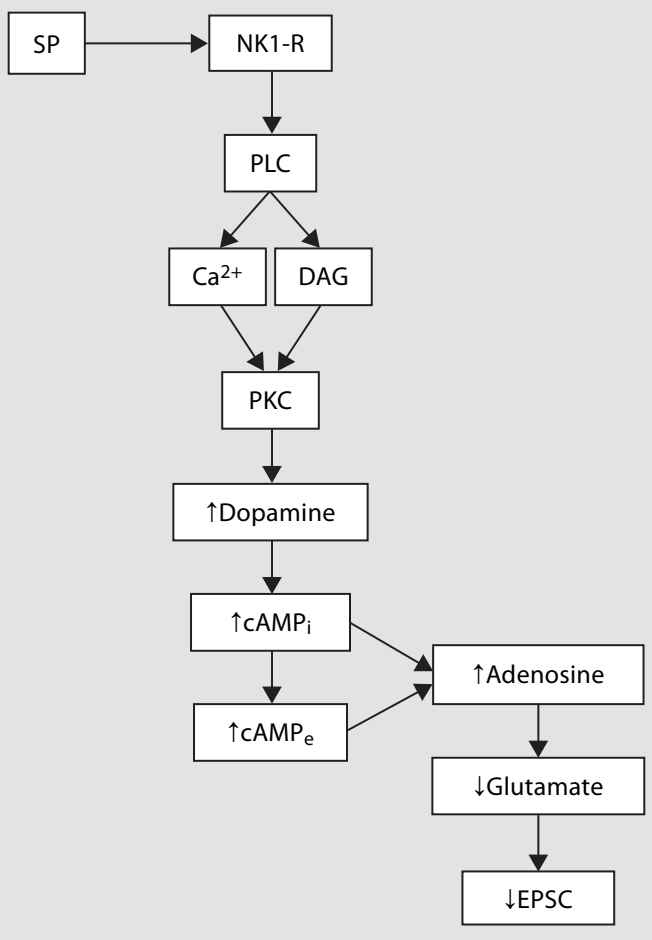

Fig. 8. Schematic diagram suggesting a possible sequence of SPinduced signalling events to decrease evoked EPSC amplitude in the NAc. $\mathrm{cAMP}_{\mathrm{i}}=$ Intracellular cAMP; $\mathrm{cAMP}_{\mathrm{e}}=$ extracellular cAMP.

that then acts to release dopamine [27]. It is likely that both mechanisms operate together to enhance dopamine release, since the NK1 receptors are present on both of these cells and the terminals. Regardless of the mechanism involved, dopamine release is dependent on SP binding to NK1 receptors and the latter activating PKC downstream of SP binding. This is suggested by the fact that SP, acting on its preferred receptors, is reported to activate PKC in several systems [28-32]. The location and relative distribution of SP NK1 receptors and their activity in the NAc and other brain regions [29, 33-35] is therefore a logical explanation of the sequencing of a signalling cascade that activates PKC to modulate the release of dopamine.

PKC appears to perform an obligatory function in NAc SP signalling to achieve the observed EPSC depression, since prior inhibition or maximal activation of $\mathrm{PKC}$ prevents or occludes the SP-induced EPSC depression.
PKC's role is therefore likely to be a modulation of dopamine release from dopaminergic terminals and acetylcholine from the cholinergic interneurons, the latter transmitter acting to enhance the release of the former, a proposition supported by the fact that this has been observed in other systems [28]. Thus, PKC acts to facilitate dopamine release from their terminals, either through its direct action on dopaminergic terminals or indirectly through its action on the cholinergic interneurons. Dopamine then acts on postsynaptic D1 receptors, in concert with NMDA receptor activation, to elevate cellular cAMP levels in the postsynaptic neuron [21].

Activation of adenylyl cyclase by dopamine acting on the D1 receptors to generate adenosine is supported by the study of Missale et al. [36]. Although SP is able to activate both the adenylyl cyclase-cAMP-PKA and the PKC signalling cascades in different cell systems [28-30,37], there is no evidence indicating a direct involvement of PKA in our test system. This finding is not unusual since other investigators have previously reported cAMP-dependent processes that do not involve PKA signalling [38]. Thus, our observation in this study provides yet another example of a signalling process that is cAMP-dependent but PKA-independent.

PKC-mediated facilitation of dopamine release [39] and generation of cAMP, which acts as a source of adenosine, is an attractive explanation for SP signalling in this nucleus. The role of dopamine D1 receptors is to generate CAMP, and cAMP to serve as a source of adenosine that acts presynaptically via the A1 receptors to depress EPSCs [21, 40, 41]. The findings of Chergui and Lacey [42] lend support to our finding here of an involvement of PKC in the SP-induced excitatory synaptic depression.

We have thus proposed a unifying model of SP signalling in the NAc to depress evoked EPSCs. In this model, SP acts on NK1 receptors located on dopaminergic terminals and on cholinergic interneurons in the NAc to activate PKC. The PKC activation facilitates dopamine release from their terminals that may be enhanced by acetylcholine from the cholinergic interneurons [25]. The released dopamine then acts on postsynaptic dopamine-D1 receptors on the medium spiny neurons to activate adenylyl cyclase, resulting in elevation in intracellular levels of cAMP. The cAMP thus produced is then either metabolized intracellularly by PDEs or is shunted to the synaptic cleft where it is metabolized to adenosine [40]. Once formed, adenosine then acts on presynaptic adenosine $\mathrm{A} 1$ receptors on incoming glutamate afferents to depress glutamate release, and thus cause EPSC depression (fig. 8). 
This model is very much a simplified attempt to explain intricate phenomena occurring in a system of complex spatiotemporal relationships between incoming signals, modulatory processes and synaptic outputs that involve multiple mediators. Further work is needed to demonstrate a biochemical interaction between SP and $\mathrm{PKC}$ in this nucleus, to elucidate the actual process of facilitation of PKC-mediated dopamine release from dopaminergic terminals and their modulation by cholinergic interneurons, and to elucidate the processes leading to generation of extracellular adenosine that mediates the synaptic depression. Another important issue worthy of further investigation is that PKC comprises a family of three different classes and at least ten different isoforms, some of which have been implicated in accumbal synaptic signalling [43-46]. More research is needed in order to reveal the role of this key signalling enzyme in the NAc and to clarify the significance of the different isoforms in this brain region, which is so critical to many complex behaviours and pathologic conditions.

\section{Conclusion}

In summary, this study has provided a plausible signal transduction mechanism through which SP produces its depressant effects on synaptic transmission in the NAc. The model is not complete since some proposed steps still need to be verified biochemically. This however constitutes a rationale for carrying out further investigations to verify the putative steps of the SP-mediated synaptic depression.

\section{References}

-1 Thomas MJ, Malenka RC, Bonci A: Modulation of long-term depression by dopamine in the mesolimbic system. J Neurosci 2000;20: 5581-5586.

$\checkmark 2$ Hoffman AF, Lupica CR: Direct actions of cannabinoids on synaptic transmission in the nucleus accumbens: a comparison with opioids. J Neurophysiol 2001;85:72-83.

$>3$ Tzschentke TM, Schmidt WJ: Functional relationship among medial prefrontal cortex, nucleus accumbens, and ventral tegmental area in locomotion and reward. Crit Rev Neurobiol 2000;14:131-142.

$\checkmark 4$ Martin G, Ahmed SH, Blank T, Spiess J, Koob GF, Siggins GR: Chronic morphine treatment alters NMDA receptor-mediated synaptic transmission in the nucleus accumbens. J Neurosci 1999;19:9081-9089.

$\checkmark 5$ Sesack SR, Deutch AY, Roth RH, Bunney BS: Topographical organization of the efferent projections of the medial prefrontal cortex in the rat: an anterograde tract-tracing study with Phaseolus vulgaris leucoagglutinin. J Comp Neurol 1989;290:213-242.

6 Pennartz CM, Groenewegen HJ, Lopes da Silva FH: The nucleus accumbens as a complex of functionally distinct neuronal ensembles: an integration of behavioural, electrophysiological and anatomical data. Prog Neurobiol 1994;42:719-761.

$>7$ Brudzynski SM, Mogenson GJ: Association of the mesencephalic locomotor region with locomotor activity induced by injections of amphetamine into the nucleus accumbens. Brain Res 1985;334:77-84.

$>8$ Redish AD, Touretzky DS: Cognitive maps beyond the hippocampus. Hippocampus 1997;7:15-35.
>9 Snyder GL, Fienberg AA, Huganir RL Greengard P: A dopamine/D1 receptor/protein kinase A/dopamine- and cAMP-regulated phosphoprotein $(\mathrm{Mr} 32 \mathrm{kDa}) /$ protein phosphatase-1 pathway regulates dephosphorylation of the NMDA receptor. J Neurosci 1998;18:10297-10303.

10 Povlock SL, Schenk JO: A multisubstrate kinetic mechanism of dopamine transport in the nucleus accumbens and its inhibition by cocaine. J Neurochem 1997;69:1093-1105.

11 O’Donnell P, Greene J, Pabello N, Lewis BL, Grace AA: Modulation of cell firing in the nucleus accumbens. Ann NY Acad Sci 1999; 877:157-175

12 Iversen SD: Behavioural effects of substance $\mathrm{P}$ through dopaminergic pathways in the brain. Ciba Found Symp 1982;91:307-324.

13 Pennartz CM, Boeijinga PH, Kitai ST, Lopes da Silva FH: Contribution of NMDA receptors to postsynaptic potentials and pairedpulse facilitation in identified neurons of the rat nucleus accumbens in vitro. Exp Brain Res 1991;86:190-198.

14 O’Donnell P, Grace AA: Dopaminergic modulation of dye coupling between neurons in the core and shell regions of the nucleus accumbens. J Neurosci 1993;13:34563471 .

15 Kombian SB, Ananthalakshmi KV, Parvathy SS, Matowe WC: Dopamine and adenosine mediate substance P-induced depression of evoked IPSCs in the rat nucleus accumbens in vitro. Eur J Neurosci 2003;18:303-311.
16 Kombian SB, Ananthalakshmi KV, Parvathy SS, Matowe WC: Substance P depresses excitatory synaptic transmission in the nucleus accumbens through dopaminergic and purinergic mechanisms. J Neurophysiol 2003;89: 728-737.

17 Nishi A, Fisone G, Snyder GL, Dulubova I, Aperia A, Nairn AC, et al: Regulation of $\mathrm{Na}^{+}$, $\mathrm{K}^{+}$-ATPase isoforms in rat neostriatum by dopamine and protein kinase C. J Neurochem 1999;73:1492-1501.

18 Cantrell AR, Scheuer T, Catterall WA: Voltage-dependent neuromodulation of $\mathrm{Na}^{+}$ channels by D1-like dopamine receptors in rat hippocampal neurons. J Neurosci 1999; 19:5301-5310.

19 Cathala L, Paupardin-Tritsch D: Effect of catecholamines on the hyperpolarizationactivated cationic Ih and the inwardly rectifying potassium I(Kir) currents in the rat substantia nigra pars compacta. Eur J Neurosci 1999;11:398-406.

20 Kombian SB, Malenka RC: Simultaneous LTP of non-NMDA and LTD of NMDA receptor-mediated responses in the nucleus accumbens. Nature 1994;368:242-246.

21 Harvey J, Lacey MG: A postsynaptic interaction between dopamine D1 and NMDA receptors promotes presynaptic inhibition in the rat nucleus accumbens via adenosine release. J Neurosci 1997;17:5271-5280.

22 Walsh DA, Van Patten SM: Multiple pathway signal transduction by the CAMP-dependent protein kinase. FASEB J 1994;8:1227-1236.

-23 Groenewegen HJ, Wright CI, Beijer AV, Voorn P: Convergence and segregation of ventral striatal inputs and outputs. Ann NY Acad Sci 1999;877:49-63. 
24 O’Donnell P, Grace AA: Synaptic interactions among excitatory afferents to nucleus accumbens neurons: hippocampal gating of prefrontal cortical input. J Neurosci 1995; 15: 3622-3639.

25 Zhou FM, Wilson CJ, Dani JA: Cholinergic interneuron characteristics and nicotinic properties in the striatum. J Neurobiol 2002; 53:590-605.

-26 Krasnova IN, Bychkov ER, Lioudyno VI, Zubareva OE, Dambinova SA: Intracerebroventricular administration of substance $\mathrm{P}$ increases dopamine content in the brain of 6 -hydroxydopamine-lesioned rats. Neuroscience 2000;95:113-117.

27 Perez-Navarro E, Alberch J, Marsal J: Postnatal development of functional dopamine, opioid and tachykinin receptors that regulate acetylcholine release from rat neostriatal slices: effect of 6-hydroxydopamine lesion. Int J Dev Neurosci 1993;11:701-708.

-28 Parker D, Svensson E, Grillner S: Substance $\mathrm{P}$ modulates sensory action potentials in the lamprey via a protein kinase $\mathrm{C}$-mediated reduction of a 4-aminopyridine-sensitive potassium conductance. Eur J Neurosci 1997;9: 2064-2076.

29 Svensson E, Grillner S, Parker D: Synaptically evoked membrane potential oscillations induced by substance P in lamprey motor neurons. J Neurophysiol 2002;87:113121.

-30 Takano K, Stanfield PR, Nakajima S, Nakajima Y: Protein kinase C-mediated inhibition of an inward rectifier potassium channel by substance $\mathrm{P}$ in nucleus basalis neurons. Neuron 1995;14:999-1008.
31 Wajima Z, Hua XY, Yaksh TL: Inhibition of spinal protein kinase $\mathrm{C}$ blocks substance $\mathrm{P}$ mediated hyperalgesia. Brain Res 2000;877: 314-321.

Yamada K, Akasu T: Substance P suppresses GABAA receptor function via protein kinase $C$ in primary sensory neurones of bullfrogs. J Physiol 1996;496:439-449.

33 Kalivas PW, Miller JS: Substance P modulation of dopamine in the nucleus accumbens. Neurosci Lett 1984;48:55-59.

34 Boix F, Huston JP, Schwarting RK: The Cterminal fragment of substance $\mathrm{P}$ enhances dopamine release in nucleus accumbens but not in neostriatum in freely moving rats Brain Res 1992;592:181-186.

35 Zhou Q, Kindlundh AM, Hallberg M, Nyberg F: The substance P (SP) heptapeptide fragment SP1-7 alters the density of dopamine receptors in rat brain mesocorticolimbic structures during morphine withdrawal Peptides 2004;25:1951-1957.

36 Missale C, Nash SR, Robinson SW, Jaber M, Caron MG: Dopamine receptors: from structure to function. Physiol Rev 1998;78:189225.

-37 Roush ED, Kwatra MM: Human substance P receptor expressed in Chinese hamster ovary cells directly activates G(alpha q/11), G(alpha s), G(alpha o). FEBS Lett 1998;428: 291-294.

38 Chapin EM, Haj-Dahmane S, Torres G, Andrade R: The 5-HT(4) receptor-induced depolarization in rat hippocampal neurons is mediated by cAMP but is independent of I(h). Neurosci Lett 2002;324:1-4.
39 Kantor L, Gnegy ME: Protein kinase C inhibitors block amphetamine-mediated dopamine release in rat striatal slices. J Pharmacol Exp Ther 1998;284:592-598.

40 Manzoni O, Pujalte D, Williams J, Bockaert $\mathrm{J}$ : Decreased presynaptic sensitivity to adenosine after cocaine withdrawal. J Neurosci 1998;18:7996-8002.

41 Nicola SM, Malenka RC: Dopamine depresses excitatory and inhibitory synaptic transmission by distinct mechanisms in the nucleus accumbens. J Neurosci 1997; 17: 5697-5710

42 Chergui K, Lacey MG: Modulation by dopamine D1-like receptors of synaptic transmission and NMDA receptors in rat nucleus accumbens is attenuated by the protein kinase C inhibitor Ro 32-0432. Neuropharmacology 1999;38:223-231.

43 Steketee JD, Rowe LA, Chandler LJ: The effects of acute and repeated cocaine injections on protein kinase $\mathrm{C}$ activity and isoform levels in dopaminergic brain regions. Neuropharmacology 1998;37:339-347.

44 Olive MF, Hodge CW: Co-localization of PKC-epsilon with various GABA(A) receptor subunits in the mouse limbic system. Neuroreport 2000;11:683-687.

45 Gordon AS, Yao L, Jiang Z, Fishburn CS, Fuchs S, Diamond I: Ethanol acts synergistically with a D2 dopamine agonist to cause translocation of protein kinase C. Mol Pharmacol 2001;59:153-160.

-46 Hopf FW, Mailliard WS, Gonzalez GF, Diamond I, Bonci A: Atypical protein kinase C is a novel mediator of dopamine-enhanced firing in nucleus accumbens neurons. J Neurosci 2005;25:985-989. 